\title{
Manual of paediatric intensive care: Pre and postoperative guidelines by Manoj Luthra
}

\author{
Publisher: Elsevier, India, 2012, pages 314, ISBN: 978-81-312-3050-3
}

\section{Harinder Singh Bedi}

Published online: 8 February 2013

(C) Indian Association of Cardiovascular-Thoracic Surgeons 2013

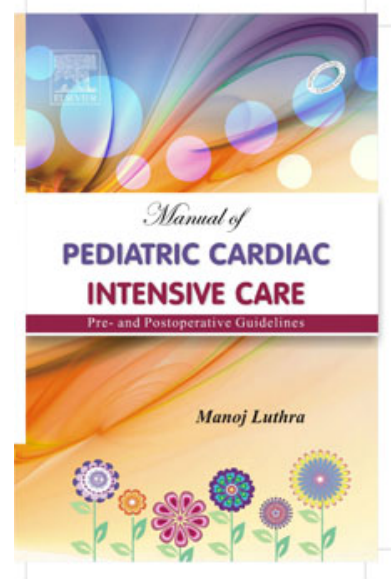

The care of critical post cardiac surgical repair children is challenging and needs training and knowledge of neonatal, infant and child anatomy and physiology and the complex interactions of the disease state, cardiopulmonary bypass and the effects of surgery. This book-masterfully written by a senior Cardiothoracic Surgeon (and Dean of the Armed Forces Medical College Pune)_-provides comprehensive discussions of pertinent cardiac issues in the ICU setting with emphasis on perioperative care. It is a practical guide with concise and clear guidelines in black and white. From the management of cyanotic spells to the rational use of inotropes and antibiotics to ventilation, cardio-respiratory interactions, nutrition, multiorgan protection and neurological injury it covers all possible scenarios in detail.

It explains the differences in treatment in the management of neonates (as we all know - a child is not a young adult) especially in relation to myocardial function and the response to drugs. The management of an infant or child in low cardiac output post operatively is particularly challenging and can tax the most experienced surgeon.

The descriptions of drugs are well done and the dosage calculation are clear. I find the pithy one liners before most chapters particularly interesting. A detailed perusal of the book will enhance and expand the information found in general texts.

Its approach is best suited for the practising cardiac surgeon, the cardiac surgical fellow/attending, the neonatologist, the paediatrician/cardiologist helping in the care of post op babies, the anesthetist, the nursing staff and cardiac intensivists - in fact anyone involved in the care of children with heart disease. They will find that the book will expand their knowledge and help them in the 'nuts and bolts' of the care of these precious patients.

HS Bedi

H. S. Bedi $(\bowtie)$

Cardio Vascular Endovascular \& Thoracic Surgery, Christian

Medical College \& Hospital, Ludhiana 141008, Punjab, India

e-mail: drhsbedicmc@gmail.com

H. S. Bedi

e-mail: drhsbedi12@yahoo.com 